\title{
Improvement of the Ship Emergency Response Procedure in Case of Collision Accident Considering Crack Propagation during Salvage Period
}

\author{
Ivana Gledić (D), Antonio Mikulić and Joško Parunov *(D)
}

Citation: Gledić, I.; Mikulić, A.; Parunov, J. Improvement of the Ship Emergency Response Procedure in Case of Collision Accident Considering Crack Propagation during Salvage Period. J. Mar. Sci. Eng. 2021, 9, 737. https://doi.org/ $10.3390 /$ jmse9070737

Academic Editor: José A.F.O. Correia

Received: 10 June 2021

Accepted: 1 July 2021

Published: 3 July 2021

Publisher's Note: MDPI stays neutral with regard to jurisdictional claims in published maps and institutional affiliations.

Copyright: (c) 2021 by the authors. Licensee MDPI, Basel, Switzerland. This article is an open access article distributed under the terms and conditions of the Creative Commons Attribution (CC BY) license (https:// creativecommons.org/licenses/by/ $4.0 /)$.
Faculty of Mechanical Engineering and Naval Architecture, University of Zagreb, 10000 Zagreb, Croatia; ivana.gledic@fsb.hr (I.G.); antonio.mikulic@fsb.hr (A.M.)

* Correspondence: josko.parunov@fsb.hr

\begin{abstract}
Specialized procedures to help in the emergency response situations following ship accidents have been under development by the Classification Societies. Such procedures consider the hull-girder collapse as the most important failure mode, without the possibility of crack propagation caused by fluctuating wave loads. In the present study, the fatigue crack propagation in the main deck of the oil tanker damaged in collision during salvage is investigated. The shape and size of the damage are modelled using the realistic bow shape of the striking ship and historical data of ship accidents. The stress intensity factor (SIF) across the main deck of the struck ship is calculated numerically and by the method based on the available experimental results of the crack propagation in the stiffened panel. Fluctuating wave-induced stresses in short-term sea conditions during salvage are obtained by Monte Carlo simulation (MC) based on Rayleigh distribution. Cycle-by-cycle crack propagation is calculated using Paris law. Many salvage simulations are performed to cover different possible time-histories of the fatigue loading. Results of the analysis are presented as histogram of the crack increase during salvage. Parametric analysis is performed to investigate the influence of the sea state severity, initial crack size, and towing duration on the final crack size. The proposed procedure can be considered as a part of a software tool for emergency response action during salvage of damaged ship.
\end{abstract}

Keywords: oil tanker; collision; salvage; crack propagation; Monte Carlo simulation

\section{Introduction}

Research on accidental loads and the hull girder strength after collision and grounding is nowadays one of the priorities in the field of marine structures [1]. This is particularly the case for an oil tanker, as an accident involving this type of vessel can have disastrous economic and environmental repercussions. To limit the escalation of accident scenarios, the accidental limit state (ALS) is incorporated in the Harmonized Common Structural Rules [2]. Also, specialized software to help in the emergency response actions following marine accidents has been developing by the Classification Societies [3].

The main hypothesis of these developments has been that hull girder collapse would occur if the hull's maximum residual load-carrying capacity is insufficient to sustain the maximum hull girder loads applied [4]. Dominating hull girder loads are, usually considered, still-water bending moments that may increase as a consequence of flooding and wave bending moments that depend on the sea states in the time of the accident and exposure time to the sea waves [5]. Residual ultimate strength is assumed to be constant during a rescue. A possibility of crack appearance and propagation in damaged ship structure and consequent hull-girder failure because of the fluctuating wave loads are rarely studied. The number of cycles relevant for fatigue failure is the number of wave cycles encountered during the rescue of one week that could be around $60,000-80,000$. 
Therefore, the fatigue failure mode of the hull-girder needs to be investigated to clarify the relevance of the cyclic wave loading on the safety of a damaged ship structure.

Recently, the low-cycle fatigue (LCF) failure mode of a ship damaged in a collision has been investigated [6]. The LCF corresponds to the scenario where a ship encounters large wave amplitudes during the salvage, causing cyclic plasticity in some parts of the damaged hull structure. The obtained results indicated that LCF is not likely failure mode for damaged oil tankers, even for the most severe damage cases.

The crack propagation in a damaged ship caused by fluctuating stresses during rescue is studied at the conceptual level only [7-9]. In these studies, rather simple computational models were used that did not allow reaching a firm conclusion regarding the importance of fatigue crack propagation. The criterion for structural failure was the residual ultimate bending moment capacity that may be affected only by large fatigue crack. It has never been shown by credible computations that such large crack growth during the rescue period is feasible.

The aim of the present study is to propose the method for the fatigue crack propagation in ship damaged in collision during salvage. The present study is built upon previous research, where damage shape and size are modelled nearly realistic, taking bow shape and penetration depth of the striking ship into account $[5,6]$. Stress intensity factor (SIF) across the main deck of the struck ship, the most important parameter in crack propagation analysis, is determined numerically using Displacement Method and by using an expression based on the experiments of crack propagation in the stiffened panel [10]. Fluctuating wave-induced vertical wave bending moments (VWBM) of damaged ship are calculated by the seakeeping analysis, assuming stationary short-term sea conditions during salvage. Crack propagation is determined by the linear elastic fracture mechanics (LEFM), using Paris law, following recommendations of the Classification Societies for such kind of analysis [11]. Individual stress amplitudes for cycle-by-cycle crack propagation analysis are obtained by Monte Carlo (MC) simulation. The total crack increase during the salvage period is presented in the form of a histogram. Parametric analysis is then performed to investigate the influence of initial crack size and towing duration on crack propagation.

The outline of the paper is as follows: the basic theoretical background of crack propagation analysis is described firstly. The FE model of a damaged Aframax oil tanker, loading applied, and associated boundary conditions are described in Section 2, followed by a review of calculation methods for SIF and the procedure for cycle-by-cycle crack propagation. In Section 3, results are presented, and parametric analysis is performed with a modification of pertinent parameters to investigate their influence on crack propagation. A discussion regarding some of the assumptions made in this research and suggestions for practical implementation of the developed procedure are provided at the end of the paper.

\section{Methodology}

\subsection{Fatigue Crack Propagation in a Damaged Ship}

Fatigue crack propagation and failure assessment are based on the procedure and expressions provided in [11]. Fatigue life calculated from the crack propagation depends on the initial crack size, which for a ship in service can be measured during inspection or assumed. In any case, the initial surface crack size should not be less than $1 \mathrm{~mm}$ [11]. Normally, small surface cracks grow with a semi-elliptical shape into the material. After penetrating through the plate thickness, the 'through-thickness crack' propagates further in the transverse direction. The length of through-thickness crack is usually more than twice plate thickness. For a damaged ship, initial through-thickness crack size at the irregular boundary of damage in the ship hull may only be roughly assumed. In this study, a through-thickness crack size of $35 \mathrm{~mm}$ is assumed, representing the minimum possible through-thickness crack at the damage boundary. In the parametric study, a crack size of $70 \mathrm{~mm}$ is also assumed, representing a case when a larger crack appears after the sudden damage. 
The main parameter governing the crack propagation calculation is the stress intensity factor (SIF), K. Based on the opening displacement of the crack lips, there are three principle crack opening modes: Mode I (tension), Mode II (shear), and Mode III (torsion) [11]. Mode I is the most common opening mode in practice [12]. The other two modes do not occur individually, but they may occur in combination with mode I, i.e., I-II, I-III or I-II-III. However, the majority of apparent combined mode cases are reduced to mode I by nature itself. This study is therefore based on Mode I only, and only SIF $K_{I}$ is determined herein.

The SIF range (SIFR) is a parameter related to the dynamic stress range, and it is calculated by the following expression [13]:

$$
\Delta K=Y \cdot \Delta \sigma \sqrt{\pi \cdot a},
$$

where $Y$ is a geometry function, $\Delta \sigma$ is a tensile stress range, and $a$ is a crack size. In case when $\Delta K \geq \Delta K_{t h}$, the crack propagation is calculated by Paris's law:

$$
\frac{d a}{d N}=C \cdot \Delta K^{m},
$$

where $\Delta K_{t h}$ is a threshold of $\Delta K, C$ and $m$ are crack propagation law parameters; constants that depend on the material, load conditions, and corrosive environmental characteristics.

The crack growth is calculated cycle-by-cycle using the time history of stress cycles, where stress amplitudes are generated by MC simulation. The procedure is described in more detail in Sections 2.2 and 2.3. In addition, many such simulations are performed to cover different order of stress application, which generally leads to different extents of crack propagation.

\subsection{Modelling of Damaged Ship Structure}

The example ship used in the present study is an Aframax-class double-hull oil tanker. The main ship particulars are presented in Table 1. The ship structure is made of mild steel $\left(R_{e H}=235 \mathrm{~N} / \mathrm{mm}^{2}\right)$, except for longitudinally effective deck and bottom structural elements, which are made of high-tensile steel $\left(R_{e H}=315 \mathrm{~N} / \mathrm{mm}^{2}\right)$.

Table 1. Main particulars of Aframax-class double hull tanker.

\begin{tabular}{ccc}
\hline Dimensions & Symbol & Value \\
\hline Length between perp. & $L_{p p}[\mathrm{~m}]$ & 234 \\
Breadth & $B[\mathrm{~m}]$ & 40 \\
Depth & $D[\mathrm{~m}]$ & 21 \\
Draught & $T[\mathrm{~m}]$ & 14 \\
Deadweight & DWT $[\mathrm{t}]$ & 105,000 \\
\hline
\end{tabular}

Damage scenarios used for modelling damage shapes are described in $[5,6]$. Damage scenarios are based on the historical database of ship damages and accidents. Each collision scenario is described by non-dimensional vertical impact location $\left(X_{v} / D\right)$, non-dimensional damage penetration depth $\left(X_{b} / B\right)$, striking ship length, striking ship depth, and the bow shape of the striking ship. The FE ship model with collision damage is obtained from the intact ship model by removing damaged finite elements $[5,6]$. Collision scenarios are observed from the first contact between two ships until maximum penetration depth is reached. If damaged during penetration, finite elements are removed. Element elimination is done automatically by implementing the parametric striking ship model [14]. Removal of the elements is based upon overlap between geometry of striking and struck ship. If there is overlapping between geometry, elements (on struck model) are completely removed regardless if they are only deformed or totally damaged. Such modelling of damage shape is called "near realistic" and it is elaborated in detail in ref. [5,6]. More realistic approach would be to model damage by collision simulation and then to refine deformed elements on damage boundary for crack propagation analysis [15]. This approach is still considered 
as too complicated, especially as one of the goals of this research is to make fast calculation of crack propagation with available tools, mainly using linear elastic fracture mechanics. Problem of further crack initiation and bifurcation on deformed elements requires a plastic fracture mechanics and would require extensive calculations, beyond the scope of the present study.

A total of 50 random damage scenarios are defined in [5,6], while only one characteristic damage case, with parameters defined in Table 2 , is used in the present study.

Table 2. Parameters of the characteristic collision scenario.

\begin{tabular}{ccccc}
\hline $\begin{array}{c}\text { Vertical } \\
\begin{array}{c}\text { Impact Location } \\
\left(\boldsymbol{X}_{\boldsymbol{D}} / \boldsymbol{D}\right)\end{array}\end{array}$ & $\begin{array}{c}\text { Damage } \\
\text { Penetration } \\
\left(\boldsymbol{X}_{\boldsymbol{B}} / \boldsymbol{B}\right)\end{array}$ & $\begin{array}{c}\text { Striking Ship } \\
\text { Length } \\
(\boldsymbol{L})[\mathrm{m}]\end{array}$ & $\begin{array}{c}\text { Striking Ship } \\
\text { Depth } \\
(\boldsymbol{D})[\mathrm{m}]\end{array}$ & $\begin{array}{c}\text { Striking Ship } \\
\text { Breadth } \\
(\boldsymbol{B})[\mathrm{m}]\end{array}$ \\
\hline 0.055 & 0.131 & 258.8 & 22.9 & 41.6 \\
\hline
\end{tabular}

A detailed description of all damage scenarios and illustrative figures are given in [6] and therefore is not reproduced herein. The damage case described in Table 2 is considered representative of a major collision accident as there is a rupture of the main deck, side shell, and inner hull of the ship.

\subsection{Computational Methods for Stress Intensity Factor (SIF)}

FE analysis is carried out using FEMAP with NX Nastran software. During the collision, the forecastle of the striking ship penetrates through the deck of the struck ship. FE model of damaged struck oil tanker is shown in Figure 1.

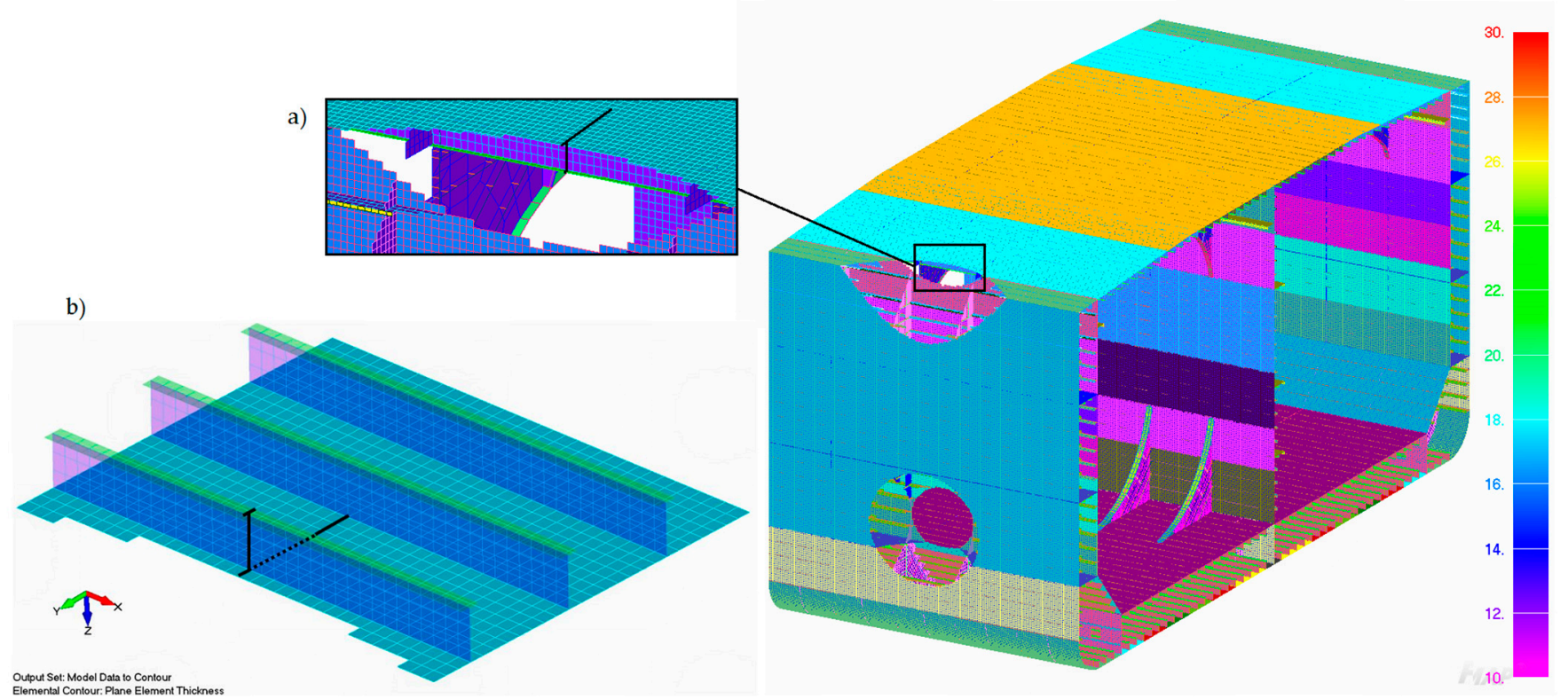

Figure 1. Damaged ship; (a) top view of assumed crack location; (b) bottom view of crack propagation path between two stiffeners.

As the concern of the present study is hull girder fatigue strength and fluctuating stresses due to vertical wave bending moments, the main attention is given to the deck structural area. Crack is assumed to originate at the farthest damage penetration point, across the main deck of the struck ship, as shown in Figure 1a. Crack is pre-determined according to the Mode I crack opening due to the symmetric boundary conditions and loading and because this crack path has the greatest contribution on overall structural integrity when considering vertical bending moment. For better visualization and under- 
standing Figure $1 \mathrm{~b}$ shows detailed crack path from origin point to second stiffener. The damaged deck section is rotated 90 degrees counterclockwise with stiffeners represented as transparent.

The analysis of SIF is performed with refined elements along the predicted crack propagation path, which is assumed to be in a direction perpendicular to the maximum principal stresses. Elements around the crack tip are refined in a box-like shape. With crack length increase, this "box" is shifted along the assumed crack path (Figures 2 and 3). The crack opening is simulated by the unzip feature in FEMAP, removing all connections between elements along the crack.

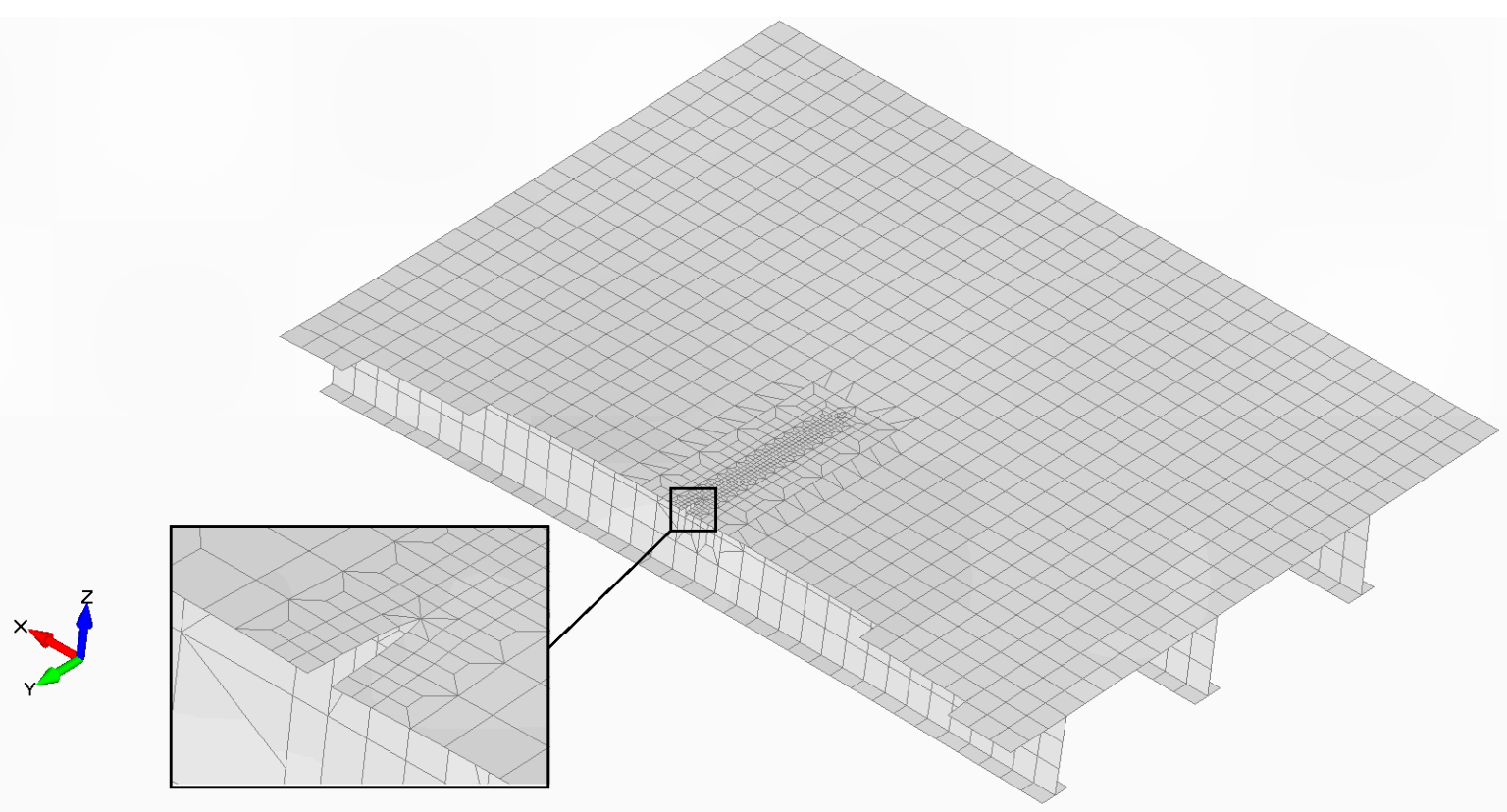

Figure 2. Crack till first stiffener.

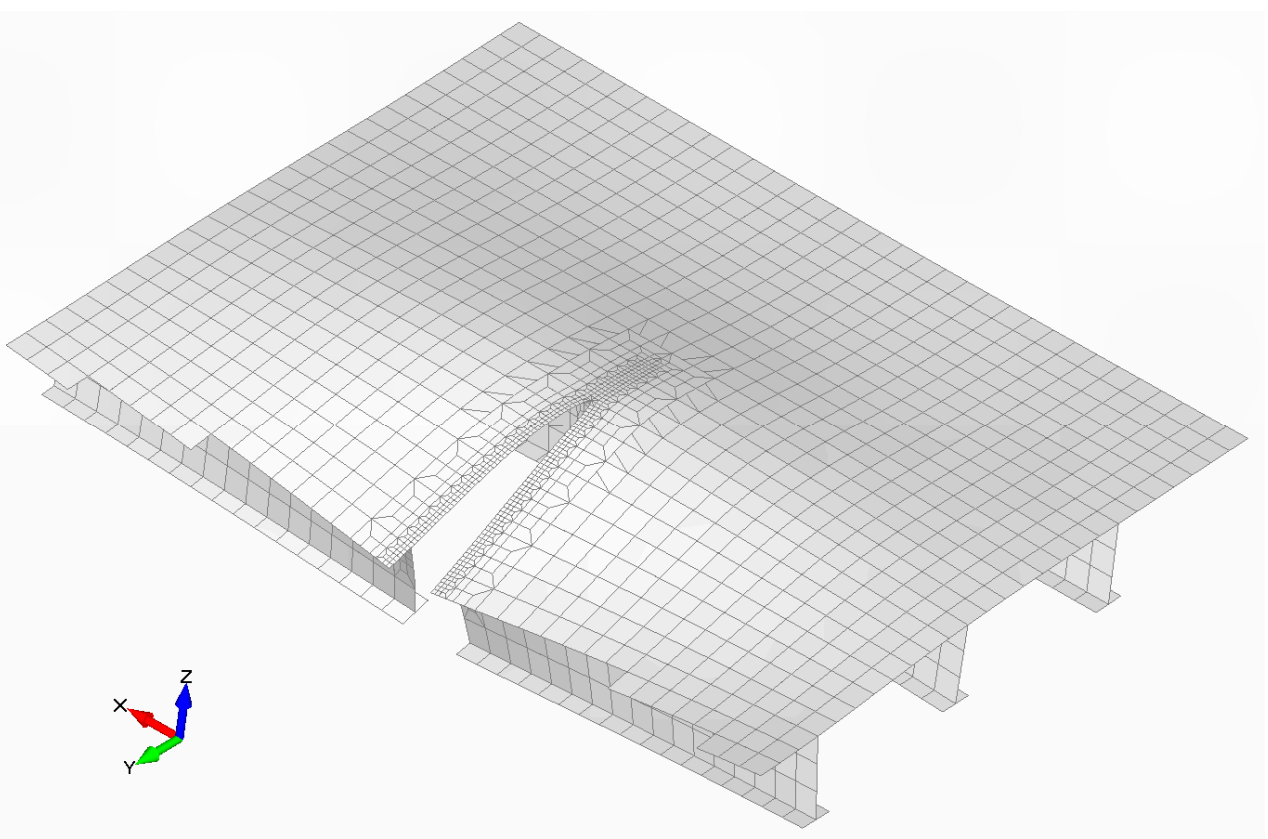

Figure 3. Crack till second stiffener. 
Mesh element size in the refined model is approximately equal to the plate thickness, $t$, which is the standard element size in the fatigue analysis of ship structural details. CQUAD parabolic plate elements with four corner nodes and four mid nodes are employed for the refinement, except around the crack tip where TRIANGLE parabolic plate elements with three corner nodes and three mid nodes are used.

SIF calculation in a stiffened panel is generally possible through the application of analytical, numerical, and experimental methods. All methods for calculation of SIF attempt to somehow relate the SIF to certain physical quantities around the crack tip, such as displacement, nodal forces, or energy release. Using FE method, SIF calculation can be done with: (1) Displacement Method along crack face [16], (2)Weight Function Method where SIF equals integral of the product of weight function and the distribution of stress along assumed crack line [17], (3) Force Method which calculates forces on nodes along a ligament at a certain distance from the crack tip [18] and (4) Griffith Energy Method or J-integral method based on potential energy released when a crack propagates [19]. In the present study, the analysis is carried out using FEMAP with NX Nastran software by Displacement Method.

From the FE analysis, using the Displacement Method $\Delta K_{I}$ is calculated according to $[16,20]$ :

$$
\Delta K_{I}=\frac{E \Delta y_{q p n}}{4} \sqrt{\frac{2 \pi}{r}} .
$$

where $E$ is the Young modulus, $\Delta y_{q p n}$ is the displacement of the quarter-point node in the direction normal to the crack plane, and $r$ is the distance from the crack tip to this quarter-point node. Based on $\Delta K_{I}$ from $F E$ analysis, geometry function $Y$ can be determined from Equation (1) as follows:

$$
Y=\frac{\Delta K_{I}}{\Delta \sigma_{n} \cdot \sqrt{\pi a}} .
$$

Vertical bending moment is applied to the FE model (Figure 1) using the standard assumption of linearly distributed strain along the cross-section in the vertical direction. Bending moment is imposed on the model boundary as enforced rotation around the control point, located at the neutral axis. The magnitude of the rotation is such that the nominal stress across the main deck in the intact condition reads $100 \mathrm{MPa}$. Based on such defined nominal stress range, SIFR is calculated by the described procedure using Displacement Method and Equation (3). Then, by employing Equation (4), geometry function $Y$ is calculated along the crack path. The red line in Figure 4 shows the geometry function distribution along the crack propagation path. Results for geometry function are compared to other studies dealing with crack propagation in stiffened panels, e.g., [10,21,22], showing the same general trend of geometry function The sharp increase of $Y$ when the crack passes the first stiffener is the consequence of the unrealistic assumption that the stiffener is immediately broken at this point. The experimental investigation has been performed, showing a smooth transition due to the partly intact stiffener over a certain time [10]. It was proposed in [10] that crack propagation through a stiffened panel may be approximated by crack propagation through the unstiffened plate, with a simple correction factor accounting for the effect of stiffeners.

SIFR for crack propagation through damaged main deck may therefore be approximated as propagation through a semi-infinite plate with stiffener correction factor:

$$
\Delta K_{I}=\frac{2 \cdot b_{s} \cdot t+A_{s}}{2 \cdot b_{s} \cdot t} \cdot 1.122 \Delta \sigma_{n} \sqrt{\pi \cdot a}
$$

where the first term represents stiffener correction factor, while $1.122 \Delta \sigma_{n} \sqrt{\pi \cdot a}$ represents SIFR for edge crack in semi-infinite plate [23]; $b_{s}$ is the distance between stiffeners; $t$ is plate thickness while $A_{S}$ is a cross-sectional area of one stiffener. Stiffener dimensions are provided in Table 3. The geometry function calculated according to Equation (5) reads 1.25. Compared with results obtained by the Displacement Method, it is found that this value 
represents approximately a mean value of the numerically obtained geometry function, and it is plotted as a blue line in Figure 4. This value of the geometry function is used in the further analysis of crack propagation as it is simpler and more realistic compared to the $Y$ calculated by the Displacement Method.

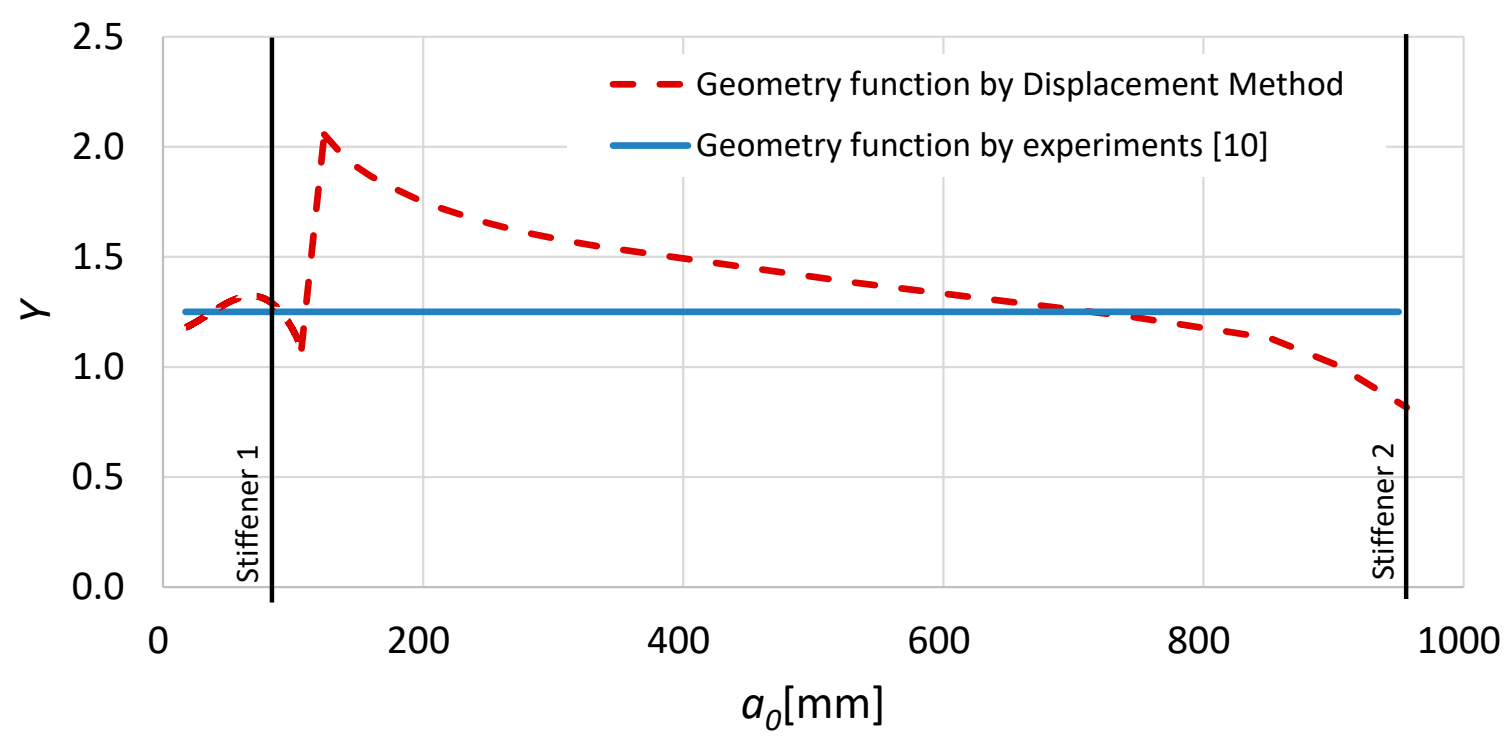

Figure 4. Geometry function $Y$.

Table 3. Characteristics of the plate and T-shaped stiffener $360 \times 12 / 140 \times 22$.

\begin{tabular}{cc}
\hline Parameter & Value \\
\hline$A_{s}\left[\mathrm{~m}^{2}\right]$ & 0.0074 \\
$t[\mathrm{~m}]$ & 0.0175 \\
$b_{S}[\mathrm{~m}]$ & 0.85 \\
\hline
\end{tabular}

\subsection{Monte-Carlo Simulation of Wave-Induced Vertical Bending Moment (VWBM)}

After a collision accident, the ship is subjected to some specific constant sea states until the salvage and rescue operation is completed. The salvage period during which the ship is towed to a safe port may vary from a few hours to few days, depending primarily on the location of the ship collision and weather conditions. According to Lee et al. [24], the design requirement for the damaged ship hull is to survive for four days in mean sea conditions. To apply the developed procedure on a ship subjected to such constant wave conditions, a careful definition of the sea states is necessary, in terms of significant wave height, zero crossing wave period, and wave angle. For this analysis, five different realistic wave scenarios are selected based on the wave scatter diagram of Sea Area 16 in the North Atlantic and Douglas sea scale $[25,26]$. Credible sea states for the analysis of the damaged ship are specified in Table 4, while only head waves are considered. Standard deviation $s$, for specific short-term condition, is obtained by the standard response prediction procedure by assuming the Pierson-Moskowitz wave spectrum. Crack propagation is assumed to be induced only by fluctuating global VWBM, while response amplitude operators (RAOs) of VWBM are calculated by closed-form expressions developed by Jensen and Mansour [24]. 
Table 4. The significant wave height $\left(H_{S}\right)$ of each sea state and its corresponding zero crossing period $\left(T_{z}\right)$ in Sea Area 16 for 4 days salvage period.

\begin{tabular}{ccccc}
\hline Sea State & $\boldsymbol{H}_{\boldsymbol{s}}[\mathrm{m}]$ & $\boldsymbol{T}_{\boldsymbol{z}}[\mathrm{m}]$ & $\boldsymbol{n}_{\boldsymbol{c}}$ [cycles] & $s[\mathrm{MNm}]$ \\
\hline 3 & 1.25 & 7.5 & 46,080 & 43.9 \\
4 & 2.5 & 8 & 43,200 & 113.1 \\
5 & 4 & 8.5 & 40,659 & 199.3 \\
6 & 6 & 9 & 38,400 & 319.3 \\
7 & 9 & 10 & 34,560 & 512.2 \\
\hline
\end{tabular}

The number of wave cycles $n_{c}$ presented in Table 4 depends on the mean wave zero crossing period $T_{z}$ and salvage period $T_{S}$ as:

$$
n_{c}=\frac{T_{s}}{T_{z}} .
$$

The individual amplitudes of VWBM in each load cycle are obtained by using the MC simulation [27]. A random amplitude of VWBM in each wave cycle is simulated using the following expression obtained from Raleigh distribution:

$$
M_{V B M}=\mathrm{s} \cdot(-2 \ln c)^{\frac{1}{2}},
$$

where $c$ is the random number with uniform distribution in the interval $[0,1]$.

\subsection{Analysis of Crack Propagation during a Salvage}

As the results of crack propagation depend on the order of stress application, 5000 different simulations of wave cycles during the salvage period are performed. Each of the simulations $\left(n_{s}\right)$ starts with the initial crack size $a_{0}$. The individual amplitudes of VWBM for each wave cycle are generated by MC simulation, as described in the previous Section, with parameters specified in Table 4 .

The nominal applied stress amplitude $\sigma_{\text {nom }}$ is calculated as the ratio of VWBM generated by MC simulation and section modulus $W$ of the ship:

$$
\sigma_{\text {nom }}=\frac{M_{V B M}}{W},
$$

where section modulus $W$ reads $32 \mathrm{~m}^{3}$.

Nominal stress range $\Delta \sigma_{\text {nom }}$ is given as:

$$
\Delta \sigma_{\text {nom }}=2 \cdot \sigma_{\text {nom }} .
$$

Using Equation (2) and corresponding parameters $C, m$, and $a_{0}$, crack propagation in one load cycle is calculated with the following expression:

$$
\frac{\Delta a_{i}}{\Delta N_{i}}=C \cdot\left(Y_{i-1} \cdot \Delta \sigma_{\text {nom }, i} \cdot \sqrt{\pi \cdot a_{i-1}}\right)^{m} .
$$

For small increments during one load cycle, $\Delta N=1$, then crack growth $\Delta a_{i}$ after one cycle, and new crack size $a_{i}$ read:

$$
\begin{gathered}
\Delta a_{i}=C \cdot\left(Y_{i-1} \cdot \Delta \sigma_{\text {nom }, i} \cdot \sqrt{\pi \cdot a_{i-1}}\right)^{m}, \\
a_{i}=a_{i-1}+\Delta a_{i} .
\end{gathered}
$$

A crack will propagate with each new cycle. When a total number of VWBM cycles in the salvage period is reached, the final crack size $a_{f}$ is achieved. A procedure for calculation of the crack propagation during the salvage period is implemented using the MATLAB R2020b [28] programming language. 


\section{Results}

The analysis is firstly performed for the "base case" combination of input parameters given in Table 5.

Table 5. Parameters for the "base case".

\begin{tabular}{cc}
\hline Parameter & Value \\
\hline Salvage period [days] & 4 \\
$C[\mathrm{MPa}, \mathrm{m}]$ & $7.27 \cdot 10^{-11}[11]$ \\
$m$ & 3 \\
$a_{0}[\mathrm{~m}]$ & 0.035 \\
\hline
\end{tabular}

The analysis is performed for sea states from Table 4 and "base case" parameters given in Table 5. Ship towing in head waves is assumed. Results of MC simulations for crack propagation rate at the end of each simulation are presented as histograms in Table 5.

Figure 5 shows that the crack increase $\Delta a$ for 4 days towing period is negligible except for SS7 when $\Delta a$ reads between 0.073 and $0.083 \mathrm{~m}$. For all Sea states, almost symmetrical bell-shaped histograms remained consistent. The average value and standard deviations of crack increase $\Delta a$ during towing in different sea states are provided in Table 6.

Sea State 3

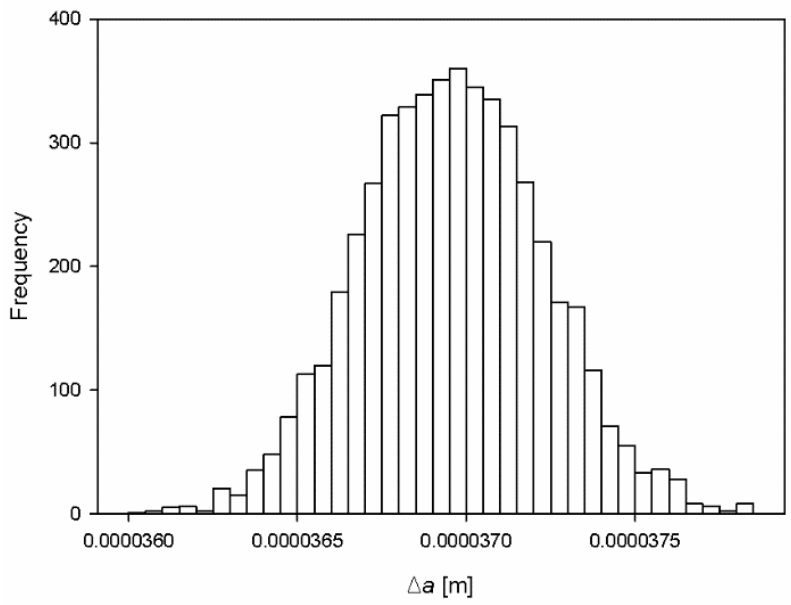

Sea State 5

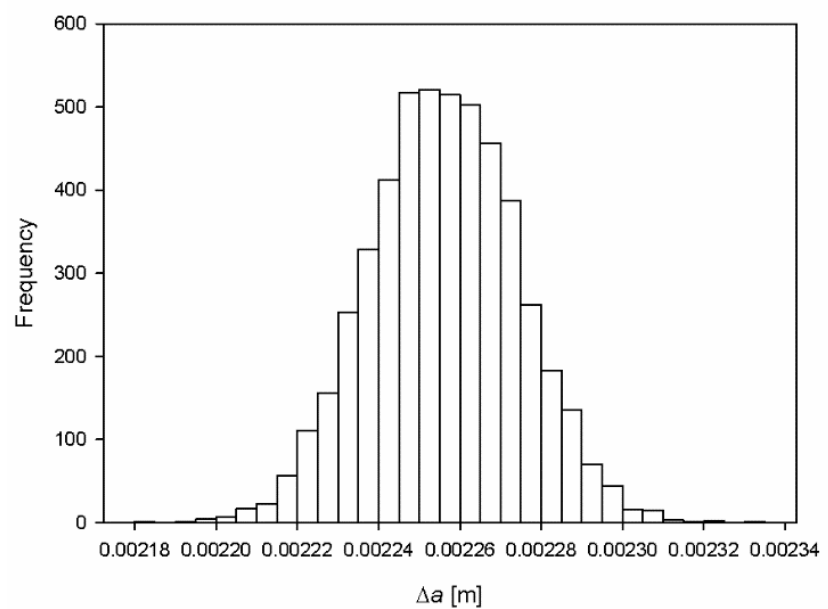

Sea State 4

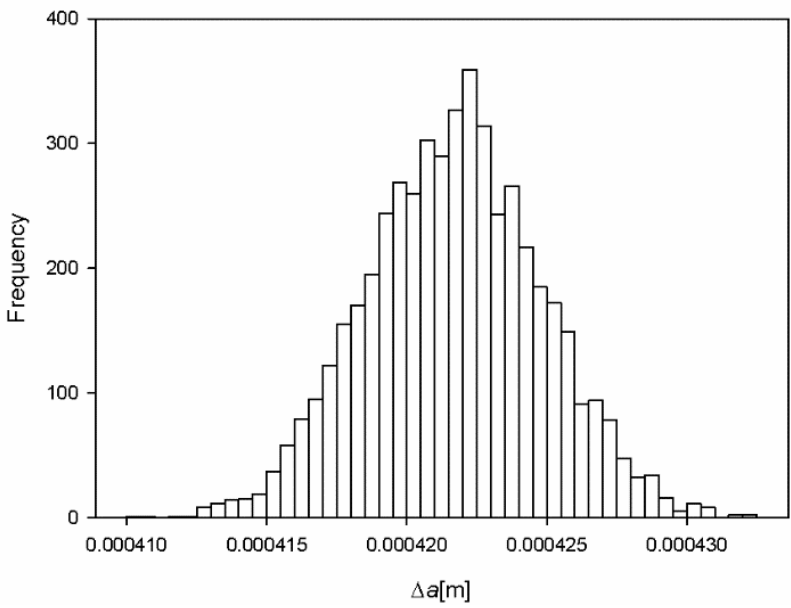

Sea State 6

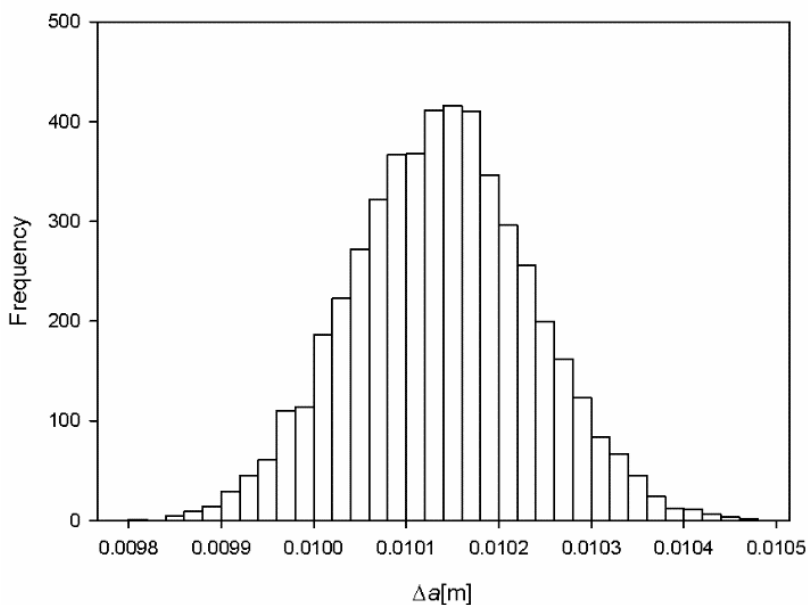

Figure 5. Cont. 
Sea State 7

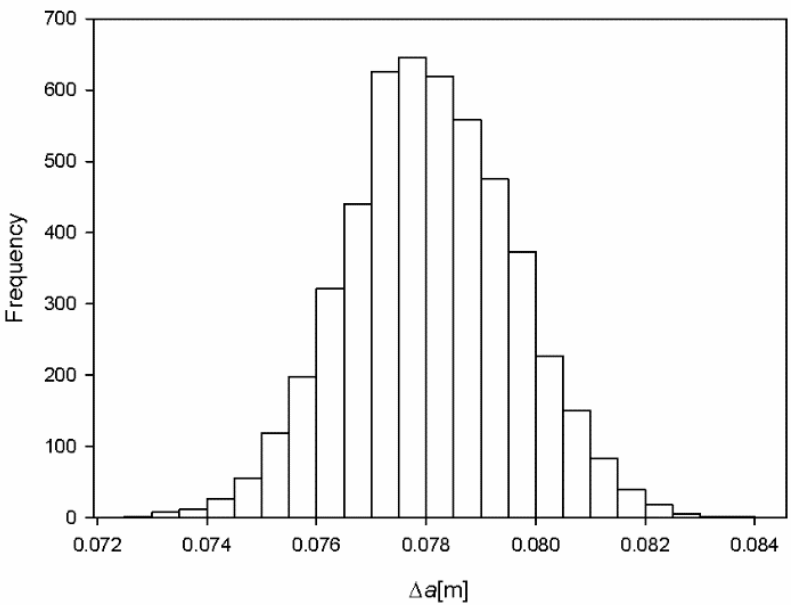

Figure 5. Histogram of 5000 simulations for each Sea state

Table 6. Mean value and standard deviation of $\Delta a$ for 4 days towing period.

\begin{tabular}{ccc}
\hline Sea State & Mean $[\mathrm{m}]$ & Standard Deviation [m] \\
\hline 3 & $3.7 \cdot 10^{-5}$ & $2.7 \cdot 10^{-7}$ \\
4 & $4.22 \cdot 10^{-4}$ & $3.13 \cdot 10^{-6}$ \\
5 & $2.26 \cdot 10^{-3}$ & $1.82 \cdot 10^{-5}$ \\
6 & $1.0 \cdot 10^{-2}$ & $9.78 \cdot 10^{-5}$ \\
7 & $7.8 \cdot 10^{-2}$ & $1.53 \cdot 10^{-3}$ \\
\hline
\end{tabular}

\section{Parametric Analysis}

Parametric analysis of fatigue crack propagation by variation of salvage period and initial crack size $a_{0}$ is performed. Variation of parameters with respect to the "base case" is given in Table 7.

Table 7. Values of parameters for parametric analysis.

\begin{tabular}{cc}
\hline Parameter & Value \\
\hline Salvage period [days] & 7 \\
$a_{0}[\mathrm{~m}]$ & 0.07 \\
\hline
\end{tabular}

As previously mentioned, the number of cycles is dependent on salvage period $T_{S}$ and calculated by Equation (6). This is presented in Table 8.

Table 8. Number of cycles for each Sea state in Sea Area 16 for salvage period of 7 days.

\begin{tabular}{cc}
\hline Sea State & $\mathbf{n}_{\mathbf{c}}$ [cycles] \\
\hline 3 & 80,640 \\
4 & 75,600 \\
5 & 71,153 \\
6 & 67,200 \\
7 & 60,480 \\
\hline
\end{tabular}

Variation of parameters $C$ and $m$ have not been considered in the parametric analysis because the literature overview showed that credible values of these parameters were lower than the value set for the "base case". Variation using a lower value of these parameters would therefore result in smaller final crack lengths. 
Results of the parametric analysis are presented in Figures 6 and 7 as crack propagation rate with the probability of exceedance of $1 \%, \Delta a(1 \%)$, for towing periods of 4 and 7 days, respectively. The crack propagation rate corresponding to $1 \%$ probability is calculated from the histogram. For the towing period of 4 days, there is almost no difference between crack increase for SS 3, 4, and 5, while it is very small for SS 6 . However, for SS 7, this difference is observable, especially for a larger initial crack size of $70 \mathrm{~mm}$. For the towing period of 7 days, as presented in Figure 7, crack propagation for $a_{0}=70 \mathrm{~mm}$ becomes unstable and leads to infinity.

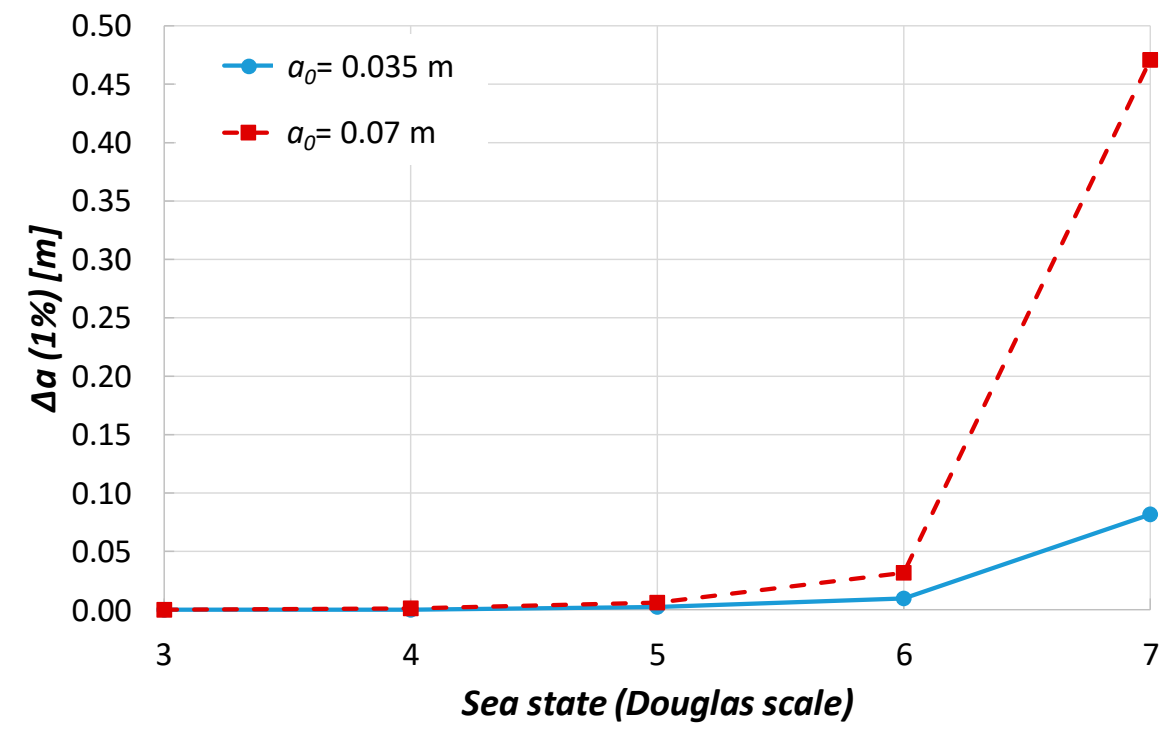

Figure 6. Crack propagation rate with the probability of exceedance of $1 \%,(\Delta a(1 \%))$ for different SS and 4 days towing period.

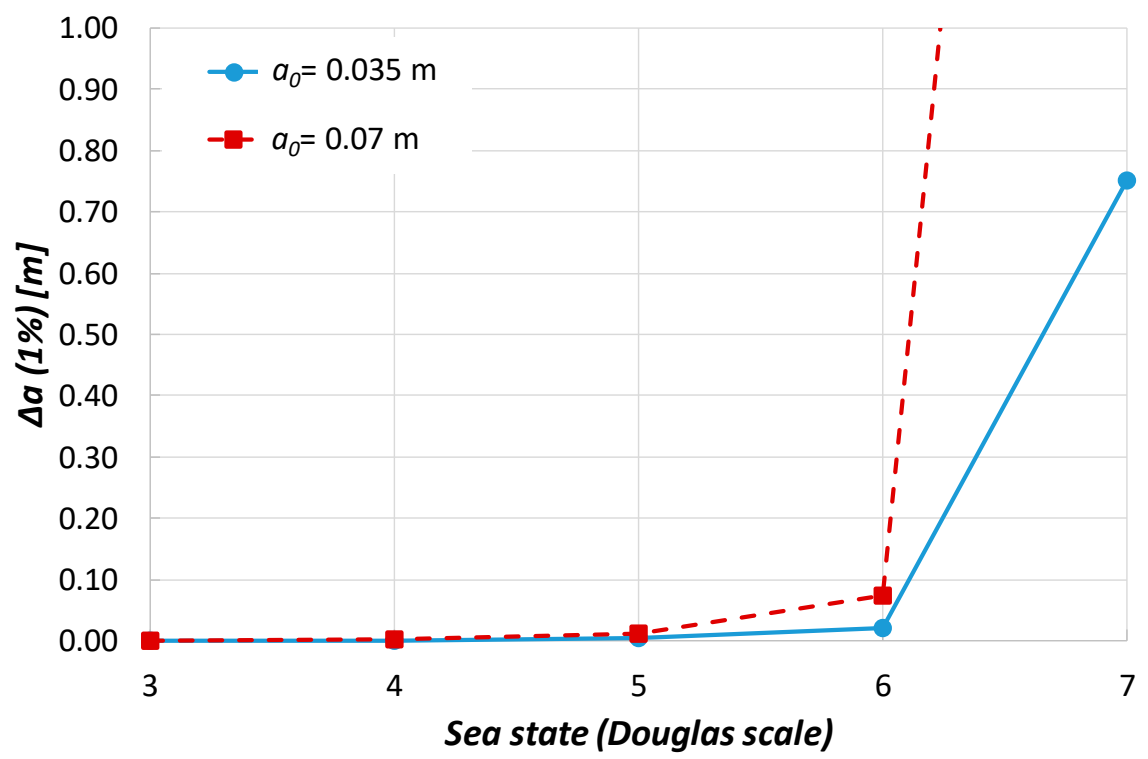

Figure 7. Crack propagation rate with the probability of exceedance of $1 \%,(\Delta a(1 \%))$ for different SS and 7 days towing period.

\section{Discussion}

The procedure developed in this study may be used for the rapid calculation of crack propagation for other types of damaged ships and different damage shapes. If the FE model of the struck ship is available in practice, a pre-defined damage scenario can be employed 
in a similar way as described in the paper. Analysis of SIF by FE method requires fine meshing, but simplified expressions given by Equation (5) may be used as an alternative.

However, in practical application FE model may not be available, or it may be impractical to use in emergency response procedure, when computational and modelling time may be the limiting factor. In that case, a 2D sectional model may be used, as, for example, obtained by MARS software [29]. Such models are often available or can be quickly generated. The 2D sectional model with simplified collision damage is shown in Figure 8. A 2D sectional model enables the determination of the stress distribution in the main deck and the assessment of the crack propagation using the procedure described in Sections 2.2 and 2.3, where SIF, given by Equation (5), may be used.

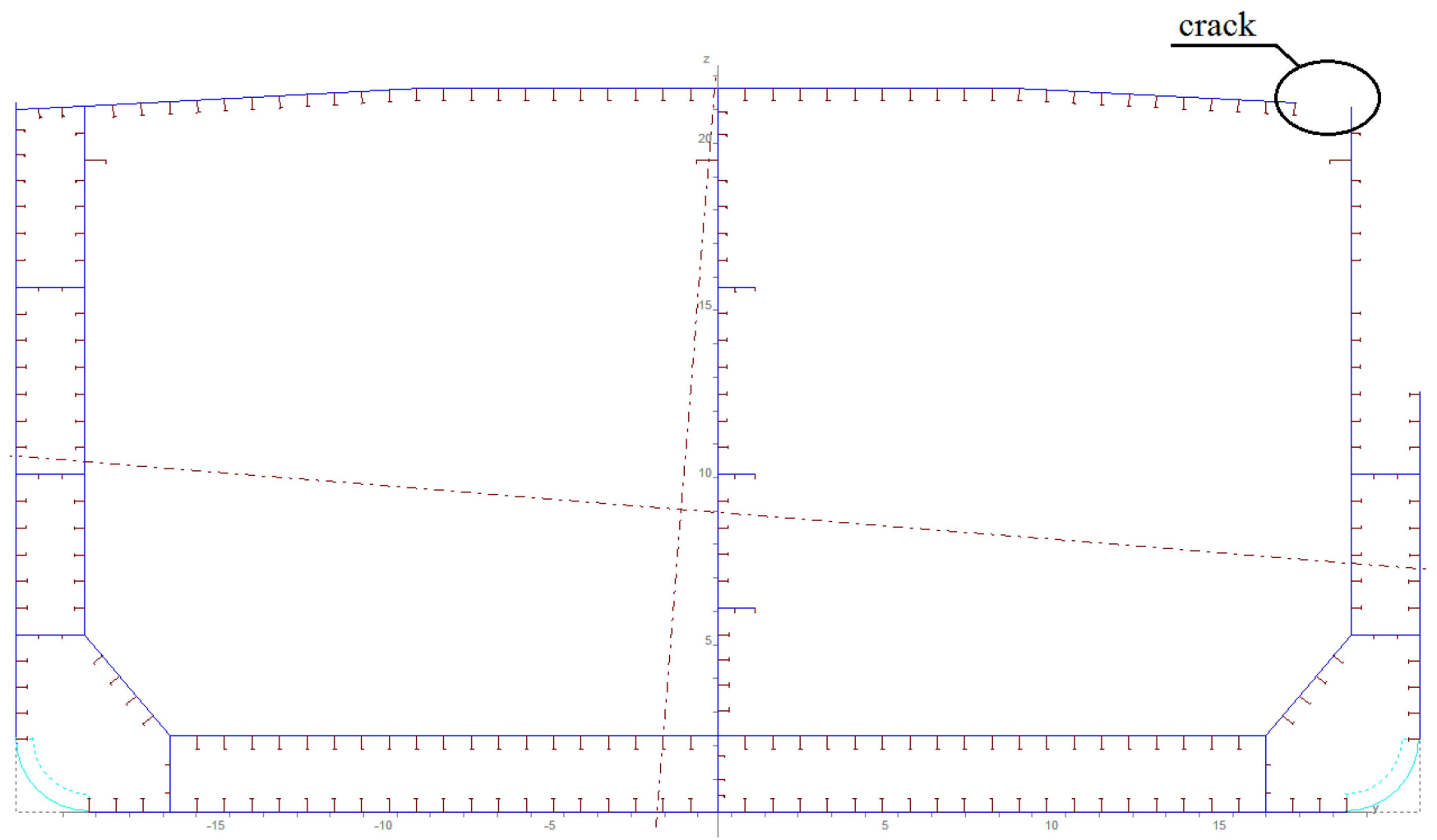

Figure 8. 2D sectional model with simplified collision damage.

The residual ultimate strength of the ship hull damaged in a collision is usually performed within emergency response procedure using progressive collapse analysis [3]. It is quite straightforward to extend such computation for the presence of fatigue crack if the crack propagation analysis shows that considerable crack during salvage may be developed. The effect of the crack on the residual strength may be simulated by deleting cracked elements, as shown in Figure 8.

Except for residual ultimate strength, the interaction between unstable fracture and collapse due to plastification needs to be considered using the Failure Assessment Diagram (FAD) [11]. This global failure mode could occur before the hull girder collapse.

Crack propagation, ultimate strength, and FAD depend not only on the dynamic (fluctuating) stress components but also on the still water stresses in a damaged condition. If the watertight integrity is compromised, effects of flooding of both cargo and void spaces and the corresponding oil outflow are to be considered [30]. The still water bending moment (SWBM) is the most important still water load component that can be significantly increased following a ship accident. In case of flooding of the cargo holds in the midship region, the tendency is to increase sagging SWBM at midship, as the weight is added in the mid-span of the ship hull girder. Such situation may decrease crack propagation in the main deck as 
compressive stresses would cause crack closure effect. On the contrary, tensile stresses in the bottom shell plating may increase and consequently enhance crack propagation. This indicates that the crack propagation in the bottom plating of a ship damaged in grounding may be dangerous. Practical methods for modelling bottom damage are described in [31].

For the considered crack location on the main deck at side, a combination of vertical and horizontal wave bending moment (HBM) may be considered as the critical load situation. If a damaged ship is found in quartering seas, the ratio of HBM to VWBM could be as large as 1.73 [32]. Even if the wave loading is only in the vertical plane, the presence of collision damage makes the ship hull structure asymmetrical and introduces asymmetrical bending loads. The neutral axis rotates and moves away from the damaged area [33]. These effects of the increase of stresses caused by combined bending moments are not considered herein.

The act of collision is complex, generating excessive deformation and residual stresses in the damaged area of the ship hull. Large plastification and bent plates are observed in the structures damaged by collision. This affects the initiation and propagation of cracks in a way that the prediction of cracks emanating from the damaged area is extremely difficult and uncertain. Experimental work and development of the numerical simulation of crashworthiness could help to resolve this issue in the future [15]. In the present study, however, the effect of large deformations around the damage opening is not considered. It should be mentioned that linear elastic fracture mechanics (LEFM) is used in the study, and plasticity zones resulting from the overload effect around crack tip are neglected, although according to [11], it plays a large role in the determination of the SIF. A closure effect from the plastic zone can reduce the SIF. The crack propagation rate decrease due to overloads is a very complex issue, and though it can provide somewhat safer results regarding the crack propagation analysis, it is typically not considered.

Only crack propagation in Mode I is considered herein that also deserves discussion. There are few reasons to consider only crack propagation in Mode I when calculating SIF. Firstly, shear stress in this specific case are rather small since the structural damage and fatigue loading are assumed as a symmetrical. This is a consequence of the assumption that the collision is perpendicular, i.e., that the striking and struck ship are at the right angle during the accident. Secondly, the analysis is in the first place intended for the analysis of the ultimate residual strength of damaged ship. For such an analysis, perpendicular crack, progressing in Mode I represent the "worst case" scenario. Finally, considering crack deflection because of Mode II and Mode III would introduce considerable complexity to the analysis.

Because of the damage shape complexity, there are many potential crack initiation locations. Consequently, multiple cracks could develop simultaneously, which could lead to the growth of the correlated cracks [34]. Such considerations are outside the scope of the present work.

Another aspect deserving attention is the consequences of the corrosion on the crack propagation. To get the impression of the corrosion influence, additional analysis is performed. The nominal stress range caused by fluctuating wave loads is increased by $10 \%$ because of the thickness diminution caused by the corrosion. This is a conservative assumption, as the section modulus for ship in service is normally reduced by less than $10 \%$. Namely, the International Association of Classification Societies (IACS) requires keeping the longitudinal strength of an aging ship at the level higher than $90 \%$ of the initial state of the new building [35]. Other parameters in this study are taken as for the "base case" given in Table 5. Results of the analysis performed for each SS and for an initial crack size of 35 $\mathrm{mm}$ are shown in Figure 9 and Table 9. Significant increase of crack propagation because of corrosion can be noticed for higher sea states. Thus, the $\Delta a(1 \%)$ is increased for SS 6 and SS 7 by $43 \%$ and $126 \%$, respectively. 


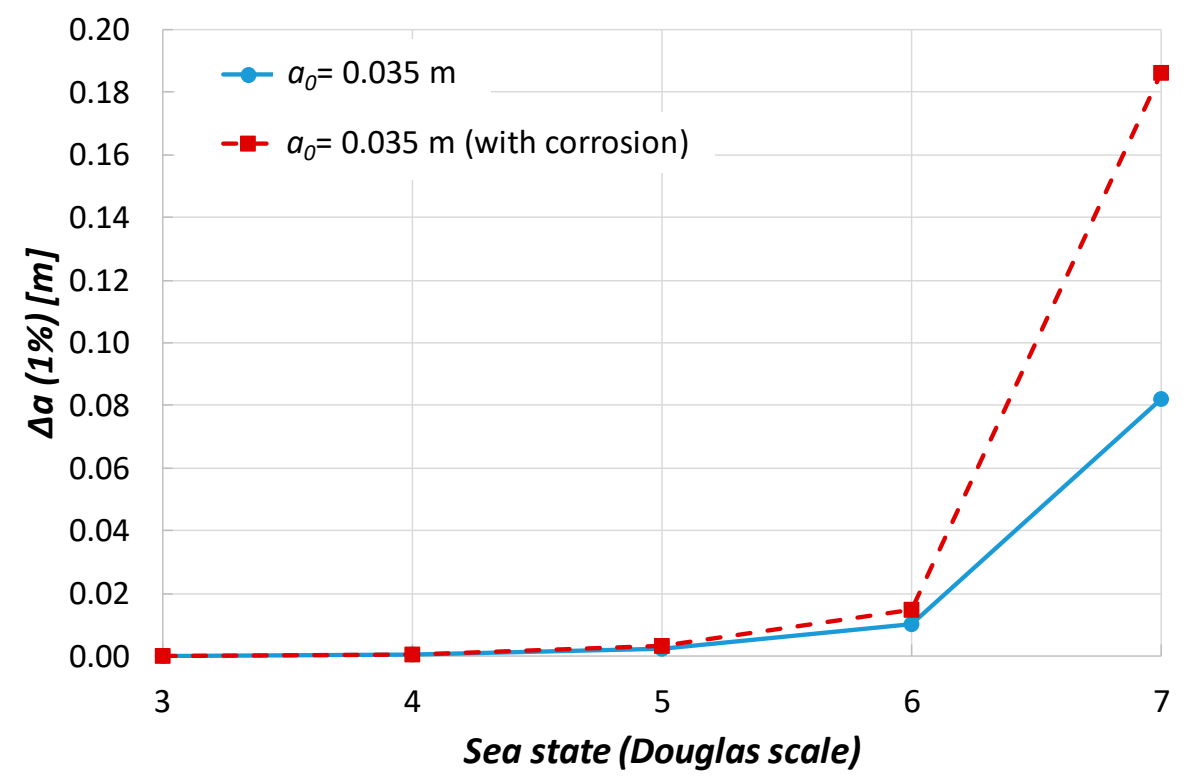

Figure 9. Comparison of crack propagation rate with probability of exceedance of $1 \%,(\Delta a(1 \%))$ for each Sea state and 4 days towing period, as-built and corroded condition.

Table 9. Increase rate of probability of exceedance $\Delta a(1 \%)$ due to corrosion.

\begin{tabular}{|c|c|c|c|}
\hline \multirow{2}{*}{ Sea State } & as-Built & Corrosion & \multirow{2}{*}{ Increase } \\
\hline & $\begin{array}{c}\Delta a(1 \%) \\
{[\mathrm{m}]}\end{array}$ & $\begin{array}{c}\Delta a(1 \%) \\
{[\mathrm{m}]}\end{array}$ & \\
\hline 3 & $3.77 \cdot 10^{-5}$ & $5.01 \cdot 10^{-5}$ & $33 \%$ \\
\hline 4 & $4.29 \cdot 10^{-4}$ & $5.74 \cdot 10^{-4}$ & $33.8 \%$ \\
\hline 5 & $2.30 \cdot 10^{-3}$ & $3.11 \cdot 10^{-3}$ & $35.2 \%$ \\
\hline 6 & $1.04 \cdot 10^{-2}$ & $1.49 \cdot 10^{-2}$ & $43.6 \%$ \\
\hline 7 & $8.21 \cdot 10^{-2}$ & $1.86 \cdot 10^{-1}$ & $126.6 \%$ \\
\hline
\end{tabular}

During rescue operations, sea conditions are not constant, especially for longer duration salvage instances. In such cases, it would be necessary to split total rescue duration in intervals with constant sea state properties. Crack propagation analysis could then be performed in principally same way as described herein. It should be mentioned that order of appearance of sea states is important, as the crack propagation is basically a non-linear process.

\section{Conclusions}

A method is proposed for the improvement of the emergency response prediction in case of a ship damaged in a collision, considering crack propagation caused by fluctuating wave loads during the salvage period. The shape and size of the damage are modelled using historical data of ship accidents. The crack propagation is based on the Paris law, while the stress intensity factor (SIF) is calculated both numerically and based on published experimental results on stiffened panels. Many Monte Carlo simulations are performed to cover different time-histories of the fatigue loading during salvage. Results of the analysis are presented as a histogram of the crack increase, where the influence of the variability of loading history is not found as very important. Parametric analysis is performed to investigate the effect of the sea state severity, initial crack size, and towing duration. Obtained results indicate that crack propagation can be significant for the Sea state 7, according to the Douglas scale $\left(H_{s}=9 \mathrm{~m}\right)$, and that crack may even become unstable for large initial crack size and long towing period. In case of damage of an aged ship, the crack could propagate faster because of the corrosion. 
The proposed procedure is intended as a starting point for the improvement of a software tool for emergency response action during the salvage of damaged ships. Ideally, 2D sectional model of the ship hull could be used within such procedure. The influence of crack propagation on the residual ultimate strength of a damaged ship can be assessed using the progressive collapse analysis method, while the unstable fracture and collapse due to plastification could be investigated using the failure assessment diagram. However, it should be mentioned that further theoretical and experimental developments are necessary to model more realistically collision damage and post-accidental behavior of damaged structure regarding crack initiation and propagation.

Author Contributions: Conceptualization, I.G. and J.P.; Methodology, I.G. and J.P.; software, I.G. and A.M.; Formal analysis, I.G. and A.M.; Investigation, I.G.; Resources, I.G. and J.P.; Writingoriginal draft preparation, I.G. and J.P.; Writing—review and editing, I.G. and J.P.; Visualization, I.G.; Supervision, J.P.; Project administration, J.P.; Funding acquisition, J.P. All authors have read and agreed to the published version of the manuscript.

Funding: The work was fundedby the Croatian Science Foundation within the projects IP-2019-042085 and IP-2014-09-8658.

Institutional Review Board Statement: Not applicable.

Informed Consent Statement: Not applicable.

Data Availability Statement: The datasets analyzed or generated in this study are available from the corresponding author upon reasonable request.

Acknowledgments: The presented work was supported by the Croatian Science Foundation within the projects IP-2019-04-2085 and IP-2014-09-8658 and derived from I.G. doctoral thesis "Propagation of Damage in Ship Structure Caused by Collision or Grounding Accident" (in Croatian), under the mentorship of J.P., also supported by the Croatian Science Foundation.

Conflicts of Interest: The authors declare no conflict of interest. The funders had no role in the design of the study; in the collection, analyses, or interpretation of data; in the writing of the manuscript, or in the decision to publish the results.

\section{References}

1. Pedersen, P.T. Marine Structures: Future Trends and the Role of Universities. Engineering 2015, 1, 131-138. [CrossRef]

2. International Association of Classification Societies (IACS). Limit states. In Common Structural Rules for Bulk Carriers and Oil Tankers (IACS CSR); International Association of Classification Societies: London, UK, 2014.

3. Wen, F. Rapid response damage assessment. In Marine Technology (mt); Kelly, D., Ed.; SNAME: Alexandria, VA, USA, October 2017; pp. 40-47. Available online: http:/ / sname.digitalwavepublishing.com/ (accessed on 8 June 2021).

4. Luis, R.M.; Teixeira, A.P.; Guedes Soares, C. Longitudinal strength reliability of a tanker hull accidentally grounded. Struct. Saf. 2008, 31, 224-233. [CrossRef]

5. Parunov, J.; Prebeg, P.; Rudan, S. Post-accidental structural reliability of double-hull oil tanker with near realistic collision damage shapes. Ships Offshore Struct. 2020, 15 sup1, S190-S207. [CrossRef]

6. Gledić, I.; Parunov, J.; Prebeg, P.; Ćorak, M. Low-cycle fatigue of ship hull damaged in collision. Eng. Fail. Anal. 2019, 96, 436-454. [CrossRef]

7. Kwon, S.; Vassalos, D.; Mermiris, G. Adopting a risk-based design methodology for flooding survivability and structural integrity in collision/grounding accidents. In Proceedings of the 11th International Ship Stability Workshop, Wageningen, The Netherlands, 21-23 June 2010; pp. 1-8.

8. Sasa, K.; Incecik, A. New Evaluation on ship strength from the view point of stranded casualties in coastal areas under rough water. In Proceedings of the 28th International Conference on Ocean, Offshore and Arctic Engineering (OMAE), Honolulu, HI, USA, 31 May-5 June 2009; pp. 43-50.

9. Bardetsky, A. Fracture mechanics approach to assess the progressive structural failure of a damaged ship. In Collision and Grounding of Ships and Offshore Structures; Amdahl, J., Ehlers, S., Leira, B.J., Eds.; Taylor \& Francis Group: London, UK, 2013; pp. 77-84.

10. Fricke, W.; Petershagen, H. Fatigue crack propagation in plate panels with welded stiffeners. In Proceedings of the Annual Assembly of International Institute of Welding, Hobart, Australia, July 1988; Volume: IIW-Doc. XIII-1272-88.

11. Bureau Veritas. Guidelines for Fatigue Assessment of Steel Ships and Offshore Units; Guidance Note NI 611 DT R00 E; Bureau Veritas: Neuilly sur Seine Cedex, France, 2016.

12. Broek, D. The Practical Use of Fracture Mechanics; Kluwer Academic Publishers: Dordrecht, The Netherlands, 1989; pp. 1-20. 
13. British Standard. Guide to Methods for Assessing the Acceptability of Flaws in Metallic Structures BS 7910; British Standards Institution: London, UK, 2005.

14. Lützen, M. Ship Collision Damage. Ph.D. Thesis, Department of Mechanical Engineering, Technical University of Denmark, Kgs. Lyngby, Denmark, 2001.

15. Ringsberg, J.; Amdahl, J.; Chen, B.; Cho, S.; Ehlers, S.; Hu, Z.; Kubiczek, J.M.; Kõrgesaar, M.; Liu, B.; Marinatos, J.N.; et al. MARSTRUCT benchmark study on nonlinear FE simulation of an experiment of an indenter impact with a ship side-shell structure. Mar. Struct. 2018, 59, 142-157. [CrossRef]

16. Guinea, V.G.; Planas, J.; Elices, M. $K_{I}$ evaluation by the displacement extrapolation technique. Eng. Fract. Mech. 2000, 66, 243-255. [CrossRef]

17. Carroll, L.B.; Tiku, S.; Dinovitzer, A.S. Rapid Stress Intensity Factor Solution Estimation for Ship Structure Applications (SSC-429); Ship Structure Committee: Washington, DC, USA, 2003.

18. De Morais, A. Calculation of stress intensity factors by the force method. Eng. Fract. Mech. 2007, 74, 739-750. [CrossRef]

19. Han, Q.; Wang, Y.; Yin, Y.; Wang, D. Determination of stress intensity factor for mode I fatigue crack based on finite element analysis. Eng. Fract. Mech. 2015, 138, 118-126. [CrossRef]

20. Laird II, G.; Epstein, S.J. Fracture mechanics and finite element analysis. Mech. Eng. 1992, 114, 69-73.

21. Dexter, R.J.; Pilarski, P.J. Crack Propagation in Welded Stiffened Panels. J. Constr. Steel Res. 2002, 58, 1081-1102. [CrossRef]

22. Dexter, R.J.; Mahmoud, H.N.; Pilarski, P. Propagation of Long Cracks in Stiffened Box-sections under Bending and Stiffened Single Panels under Axial Tension. Int. J. Steel Struct. 2005, 5, 181-188.

23. Rooke, D.P.; Baratta, F.I.; Cartwright, D.J. Simple methods of determining stress intensity factors. Eng. Fract. Mech. 1981, 14, 397-426. [CrossRef]

24. Jensen, J.J.; Mansour, A.E. Estimation of Ship Long-Term Wave-Induced Bending Moment Using Closed-Form Expressions. R. Inst. Nav. Archit. 2002, W291, 41-55.

25. Lee, Y.; Chan, H.S.; Pu, Y.; Incecik, A.; Dow, R.S. Global wave loads on damaged ship. Ships Offshore Struct. 2012, 7, 237-268. [CrossRef]

26. Sun, F.; Pu, Y.; Chan, H.S.; Dow, R.S.; Shahid, M.; Das, P.K. Reliability-Based Performance Assessment of Damaged Ships; Ship Structure Committee Report No. 459; Ship Structure Committee: Washington DC, USA, 2011.

27. Chen, N.Z. A stop-hole method for marine and offshore structures. Int. J. Fatigue 2016, 88, 49-57. [CrossRef]

28. MathWorks (Matlab Documentation). Available online: http:/www.mathworks.com/help/index.html (accessed on 8 June 2021).

29. MARS. User's Manual; Bureau Veritas: Paris, France, 2020.

30. Bužančić Primorac, B.; Ćorak, M.; Parunov, J. Statistics of still water bending moment of damaged ship. In Analysis and Design of Marine Structures; Guedes Soares, C., Shenoi, R.A., Eds.; Taylor and Francis Group: London, UK, 2015; pp. $491-497$.

31. Heinvee, M.; Tabri, K. A simplified method to predict grounding damage of double bottom tankers. Mar. Struct. 2015, 43, 22-43. [CrossRef]

32. Khan, I.A.; Das, P.K. Reliability Analysis of Intact and Damaged Ships Considering Combined Vertical and Horizontal Bending Moments. Ships Offshore Struct. 2008, 3, 371-384. [CrossRef]

33. Fujikubo, M.; Zubair, M.A.; Takemura, K.; Iijima, K.; Oka, S. Residual hull girder strength of asymmetrically damaged ships. J. Jpn. Soc. Naval Arch. Ocean Eng. 2012, 16, 131-140. [CrossRef]

34. Feng, G.Q.; Garbatov, Y.; Guedes Soares, C. Probabilistic model of the growth of correlated cracks in a stiffened panel. Eng. Fract. Mech. 2012, 84, 83-95. [CrossRef]

35. Paik, J.K.; Wang, G.; Thayamballi, A.K.; Lee, J.M.; Park, Y.I. Time-dependent risk assessment of aging ships accounting for general/pit corrosion, fatigue cracking and local denting damage. Trans. Soc. Nav. Archit. Mar. Eng. 2003, 111, 159-197. 